\title{
Carpal tunnel syndrome in the elderly Nerve conduction parameters
}

\author{
Thiago Guimarães Naves ${ }^{1}$, João Aris Kouyoumdjian²
}

\begin{abstract}
Objective: To establish nerve conduction parameters for carpal tunnel syndrome (CTS) electrodiagnosis in the elderly. Method: Thirty healthy subjects (65-86 years), 9 male and 21 female, were studied. Routine median and ulnar sensory and motor nerve conduction studies, median mixed palmar latency, comparative latency techniques median to ulnar (sensory, mixed and motor lumbrical-interossei), median to radial (sensory), and combined sensory index (CSI) were performed in both hands. Results: The upper limits of normality (97.5\%) were: median sensory distal latency $3.80 \mathrm{~ms}(14 \mathrm{~cm})$; median motor distal latency $4.30 \mathrm{~ms}(8 \mathrm{~cm})$; median palmar latency $2.45 \mathrm{~ms}(8 \mathrm{~cm})$; lumbrical-interossei latency difference $0.60 \mathrm{~ms}(8 \mathrm{~cm})$; comparative median to radial $0.95 \mathrm{~ms}(10 \mathrm{~cm})$; comparative median to ulnar $0.95 \mathrm{~ms}(14 \mathrm{~cm})$; comparative palmar median to ulnar $0.50 \mathrm{~ms}(8 \mathrm{~cm})$; and CSI $2.20 \mathrm{~ms}$. Sensory and mixed latencies were measured at peak. Conclusion: Our results establish new nerve conduction parameters for mild CTS electrodiagnosis in the elderly and will be helpful to reduce the number of false positive cases in this age.

Key words: carpal tunnel syndrome, median nerve, nerve conduction studies, normative study, aging.
\end{abstract}

\section{Síndrome do túnel do carpo em idosos: parâmetros de condução nervosa}

\section{RESUMO}

Objetivo: Estabelecer parâmetros de condução nervosa para o eletrodiagnóstico da síndrome do túnel do carpo (STC) em idosos. Método: Foram estudadas 30 pessoas idosas (65-86 anos) saudáveis. Foi realizado estudo de condução nervosa sensitiva e motora rotineira dos nervos mediano e ulnar, latência palmar mista do mediano, técnicas de comparação de latências mediano-ulnar (sensitivo, misto e motor lumbrical-interósseo) e mediano-radial (sensitivo) e índice sensitivo combinado (ISC) em ambas as mãos. Resultados: Os limites superiores de normalidade, 97,5\% foram: latência distal sensitiva do mediano 3,80 ms (14 cm); latência distal motora do mediano 4,30 ms ( $8 \mathrm{~cm})$, latência palmar do mediano $2,45 \mathrm{~ms}(8 \mathrm{~cm})$, diferença de latência lumbrical-interósseo $0,60 \mathrm{~ms}(8$ $\mathrm{cm}$ ), comparação mediano-radial 0,95 ms (10 cm), comparação mediano-ulnar 0,95 ms (14 $\mathrm{cm})$, comparação mediano-ulnar palmar 0,50 ms ( $8 \mathrm{~cm})$ e ISC 2,20 ms. As latências sensitivas e mistas foram medidas no pico. Conclusão: Nossos resultados estabelecem novos valores de condução nervosa para o eletrodiagnóstico da STC leve em idosos.

Palavras-chave: síndrome do túnel do carpo, nervo mediano, estudo de condução nervosa, valores de normalidade, envelhecimento.

Carpal tunnel syndrome (CTS), the most common entrapment neuropathy in humans, is caused by median nerve compression in the carpal tunnel, just distal to the wrist crease $\mathrm{e}^{1-3}$. The incidence ranges from 99-376 / 100,000, peaking in the early fifties, and also in the seventies in some reports ${ }^{4-8}$. The prevalence varies between $0.6 \%$ to $2.1 \%$ in males and $3.0 \%$ to $5.8 \%$ in females $^{9-10}$. The main complaints are intermittent numbness of the hands, nocturnal paresthesia, and pain. In chronic or more severe cases, weakness and thenar atrophy may appear ${ }^{2,11,12}$. In the elderly population, 
the clinical picture may be atypical, without symptoms, or even rapidly lead to severe forms with thenar atrophy ${ }^{7,13}$.

Nerve conduction studies (NCS) are the most effective diagnostic tool for CTS, having a high sensitivity and specificity ${ }^{14}$. They are also appropriate for excluding other diagnoses besides being a great utility for outcome comparisons ${ }^{15}$. The effect of aging upon the peripheral nervous system has been studied since the middle of the last century, and it is well known that aging modifies all nerve conduction parameters, including amplitude, latency, and conduction velocity ${ }^{16,17}$. Unfortunately, most reference parameters are derived from subject series under the age of 60 years and are, of course, unsuitable for CTS electrodiagnosis in the elderly. This could lead to an over-diagnosis because of an increased number of false-positives.

The main purpose of this study was to determine nerve conduction parameters for CTS diagnosis in the elderly, including sensory, mixed, motor, and comparative techniques.

\section{METHOD}

Thirty healthy volunteers were selected from November 2006 to January 2008 for this study. All volunteers were interviewed and examined by one of the authors (TGN). The inclusion criteria were a minimum age of 65 years and the absence of any upper extremity sensory complaints. Exclusion criteria were diabetes mellitus (at least one normal glycaemia in the last 6 months), peripheral neuropathy, excessive alcohol intake, thyroid diseases, leprosy, and upper limb traumatic injuries with or without peripheral nerve lesion; any kind of cancer, autoimmune disease, use of drugs that are potentially harmful to the peripheral nervous system, hepatitis B or $\mathrm{C}$, and acquired immune deficiency syndrome. There were no familial cases and none have been previously exposed to jobs considered to increase risk of CTS. These exclusion criteria were considered to be present if the volunteer made reference to a previous diagnosis or used any drugs commonly prescribed for these conditions. An intake of 21 or more units of alcohol per week for men and 14 units or more for women was considered excessive. One standard unit of alcohol was considered equal to $8 \mathrm{~g}$ of ethanol.

All NCS were performed with a Keypoint portable ${ }^{\circledR}$ electromyography machine (Medtronic, Skövlunde, Denmark). The palm, hand, and foot temperature was kept above $32^{\circ} \mathrm{C}$. A ring surface electrode was used for median and ulnar sensory NCS; the cathode-anode distance was maintained between $2-3 \mathrm{~cm}$. A bar electrode with an interelectrode distance of $3 \mathrm{~cm}$ was used for median and ulnar mixed nerve conduction, and sural and radial sensory NCS. A platinum disc electrode, $1 \mathrm{~cm}$ in diameter, was used for the median and ulnar nerve motor conduction studies; the cathode was placed on the best motor point, thenar and hypothenar, respectively, and the anode on the metacarpophalangeal bone prominence. Stimuli with a pulse duration of $0.10 \mathrm{~ms}$ for sensory nerve conduction and $0.20 \mathrm{~ms}$ for motor nerve conduction were applied until supramaximal responses were obtained. The filter bandwidth was adjusted to $20 \mathrm{~Hz}$ and $10 \mathrm{kHz}$; the sweep speed was adjusted to 1 or $2 \mathrm{~ms}$ per division; and the sensitivity was adjusted to 20 to $50 \mu \mathrm{V}$ per division for sensory and mixed NCS, and 2 to $5 \mathrm{mV}$ per division for motor NCS. All studies were performed on the right and left upper limb (median, radial, and ulnar nerves) and right lower limb (sural nerve). The NCS protocol is described below.

\section{Median nerve}

(1) Sensory distal latency (SDL), antidromic, wrist to digit II, with a fixed distance of $14 \mathrm{~cm}$, onset and peak measured; (2) sensory conduction velocity (SCV); (3) sensory nerve action potential (SNAP) amplitude, measured peak-to-peak; (4) mixed palmar latency (MPL), orthodromic, palm to wrist, with a fixed distance of $8 \mathrm{~cm}$, peak measured; (5) motor distal latency (MDL), wrist to thenar eminence, with a fixed distance of $8 \mathrm{~cm}$; (6) motor conduction velocity (MCV) of the forearm, after wrist and elbow stimulation; (7) compound muscle action potential (CMAP) amplitude, measured peak-to-peak.

\section{Ulnar nerve}

(1) SDL, antidromic, wrist to digit V, with a fixed distance of $12 \mathrm{~cm}$, onset and peak measured; (2) SCV; (3) SNAP amplitude, measured peak-to-peak; (4) MPL, orthodromic, palm to wrist, with a fixed distance of $8 \mathrm{~cm}$; (5) MDL, wrist to hypothenar, with a fixed distance of 8 $\mathrm{cm}$; (6) MCV of the forearm after wrist and elbow stimulation; (7) CMAP amplitude, measured peak-to-peak.

\section{Sural nerve}

(1) SDL, antidromic, distal leg to lateral malleolus, with a fixed distance of $14 \mathrm{~cm}$, onset and peak measured; (2) SCV; (3) SNAP amplitude, measured peak-to-peak.

\section{Radial nerve}

(1) SDL, antidromic, distal forearm to anatomical snuffbox, with a fixed distance of $12 \mathrm{~cm}$, onset and peak measured; (2) SCV; (3) SNAP amplitude, measured peakto-peak.

\section{Comparative techniques for CTS electrodiagnosis}

MUD: Sensory latency difference in the median to ulnar nerves, antidromic, wrist to ring finger, with a fixed distance of $14 \mathrm{~cm}$; latencies were measured to the peak.

MRD: Sensory latency difference in the median to ra- 
dial nerves, antidromic, wrist to thumb, with a fixed distance of $10 \mathrm{~cm}$; latencies were measured to the peak.

MUPD: Mixed latency difference median to the ulnar, orthodromic, and palm to wrist, with a fixed distance of $8 \mathrm{~cm}$; latencies were measured to the peak.

CSI: Sum of MUD, MRD, and MUPD.

LUMB: Motor latency difference in the median to ulnar nerves; CMAP were recorded on the lumbrical-interossei muscles, with a fixed distance of $8 \mathrm{~cm}^{18}$.

We also calculated the body mass index (BMI) from weight and height $\left(\mathrm{kg} / \mathrm{m}^{2}\right)$ measurements and the wrist ratio (WR) as wrist depth/width ( $\mathrm{mm} / \mathrm{mm}$ ).

Statistical analysis was performed with the Minitab 15 (Minitab Inc.) package. Nerve conduction parameters (latencies and latency differences) were analyzed using the mean and standard deviation (SD) for Gaussian, or median for non Gaussian distributions ${ }^{19}$. To check for Gaussian distribution, the Anderson-Darling test was applied. The upper limit of normality was set at the 97.5 percentile for non-Gaussian, and the mean plus 2 SD for Gaussian distributions. The one-sample t test was used for the right to left latency differences when the distribution was Gaussian; otherwise, the one-sample Wilcoxon test for median was used. A significance level $\alpha=0.05$ was adopted.

The study protocol was approved by the São José do
Rio Preto Medical School (FAMERP) Research and Ethics Committee and informed consent was obtained from all volunteers.

\section{RESULTS}

Thirty healthy elderly (30 hands) volunteers, including 21 females (70\%) and nine males (30\%), were studied. The mean age was $69.9 \pm 5.0$ (range, 65 to 86 ) years, mean BMI was $26.7 \pm 5.0 \mathrm{~kg} / \mathrm{m}^{2}$, and mean WR was $0.682 \pm 0.042$. Of the volunteers, $46.7 \%$ had systemic hypertension. Each of the following conditions was present in one volunteer each: myocardial infarction, cataract, lipid abnormalities, and osteoporosis. The drugs most commonly used were captopril (16.7\%), atenolol (13.3\%), and hydrochlorothiazide (13.3\%).

All volunteers had SNAPs, mixed, and CMAPs measured in all nerves studied, including the sural nerve. The nerve conduction parameters obtained for all techniques described for the median, ulnar, radial, and sural (sensory); median and ulnar (motor), and comparative techniques for CTS electrodiagnoses are described in Tables 1, 2, and 3 .

There were no male to female difference for mean right median SDL (2.42 versus $2.50 \mathrm{~ms}$, onset-measured, and 3.15 versus $3.27 \mathrm{~ms}$, peak-measured), for MPL (1.94 versus $2.00 \mathrm{~ms}$ ) and for all sural nerve parameters. However, all comparative techniques and MDL had higher values in female group.

Table 1. Latency and latency differences in electrodiagnostic techniques used to diagnose carpal tunnel syndrome in 30 healthy elderly subjects (30 right hands and 30 left hands).

\begin{tabular}{|c|c|c|c|c|c|c|c|}
\hline Variable & Side & Mean & Median & SD & $97.5 \%$ & $p$-value & Abnormal \\
\hline \multirow[t]{2}{*}{ SDL } & $\mathrm{R}$ & 3.24 & - & 0.28 & 3.80 & $<0.001^{* *}$ & $>3.80 \mathrm{~ms}$ \\
\hline & $\mathrm{L}$ & 3.11 & - & 0.37 & 3.73 & & \\
\hline \multirow[t]{2}{*}{ MDL } & $\mathrm{R}$ & 3.51 & - & 0.38 & 4.26 & $0.275^{* *}$ & $\geq 4.30 \mathrm{~ms}$ \\
\hline & $\mathrm{L}$ & 3.48 & - & 0.40 & 4.21 & & \\
\hline \multirow[t]{2}{*}{ MPL } & $\mathrm{R}$ & 1.98 & - & 0.22 & 2.43 & $0.278^{* *}$ & $\geq 2.45 \mathrm{~ms}$ \\
\hline & $L$ & 1.95 & - & 0.20 & 2.36 & & \\
\hline \multirow[t]{2}{*}{ MUD } & $\mathrm{R}$ & 0.31 & - & 0.35 & 0.93 & $0.217^{* *}$ & $\geq 0.95 \mathrm{~ms}$ \\
\hline & $L^{*}$ & - & 0.10 & - & 0.93 & & \\
\hline \multirow[t]{2}{*}{ MRD } & $\mathrm{R}$ & 0.38 & - & 0.29 & 0.93 & $0.559 * *$ & $\geq 0.95 \mathrm{~ms}$ \\
\hline & $L^{*}$ & - & 0.25 & - & 0.83 & & \\
\hline \multirow[t]{2}{*}{ MUPD } & $\mathrm{R}$ & 0.13 & - & 0.20 & 0.49 & $0.684^{* *}$ & $\geq 0.50 \mathrm{~ms}$ \\
\hline & $L$ & 0.12 & - & 0.22 & 0.49 & & \\
\hline \multirow[t]{2}{*}{ CSI } & $\mathrm{R}$ & 0.82 & - & 0.75 & 2.17 & $0.275^{* *}$ & $\geq 2.20 \mathrm{~ms}$ \\
\hline & $L^{*}$ & - & 0.52 & - & 2.18 & & \\
\hline \multirow[t]{2}{*}{ LUMB } & $\mathrm{R}$ & 0.24 & - & 0.22 & 0.60 & $0.153^{\#}$ & $>0.60 \mathrm{~ms}$ \\
\hline & $L^{*}$ & - & 0.10 & - & 0.53 & & \\
\hline
\end{tabular}

*Variables with non-Gaussian distribution; ** right to left difference with Gaussian distribution: one-sample t-test; ${ }^{*}$ right to left difference with non-Gaussian distribution: one-sample Wilcoxon test. SD: standard deviation; SDL: median sensory distal latency; MPL: median mixed palmar latency; MUD: median to ulnar nerve sensory difference (ring finger); MRD: median to radial sensory difference (thumb); MUPD: median to ulnar mixed palmar difference; CSI: combined sensory index; LUMB: median to ulnar lumbrical-interossei difference; MDL: median motor distal latency; R: right; L: left. 
Table 2. Sensory nerve conduction parameters in 30 healthy elderly subjects: 60 upper limbs (30 right and 30 left sides) and 30 lower limbs (only the right side).

\begin{tabular}{|c|c|c|c|c|c|c|}
\hline Nerve & Variable & Side & $97.5 \%$ & $2.5 \%$ & $p$-value & Abnormal \\
\hline \multirow[t]{6}{*}{ Median } & SDL & $\mathrm{R}^{*}$ & $2.83 \mathrm{~ms}$ & - & $0.014^{* *}$ & $\geq 2.85 \mathrm{~ms}$ \\
\hline & & $L$ & $2.80 \mathrm{~ms}$ & - & & \\
\hline & Amplitude & $\mathrm{R}$ & - & $13.7 \mu \mathrm{V}$ & $0.008^{\#}$ & $\leq 12.5 \mu \mathrm{V}$ \\
\hline & & $\mathrm{L}^{*}$ & - & $12.7 \mu \mathrm{V}$ & & \\
\hline & CV & $\mathrm{R}$ & - & $49.5 \mathrm{~m} / \mathrm{s}$ & $0.010^{* *}$ & $<49.5 \mathrm{~m} / \mathrm{s}$ \\
\hline & & $L$ & - & $50.0 \mathrm{~m} / \mathrm{s}$ & & \\
\hline \multirow[t]{6}{*}{ Ulnar } & $\mathrm{SDL}$ & $\mathrm{R}^{*}$ & $2.33 \mathrm{~ms}$ & - & $0.017^{* *}$ & $\geq 2.45 \mathrm{~ms}$ \\
\hline & & $L$ & $2.43 \mathrm{~ms}$ & - & & \\
\hline & Amplitude & $\mathrm{R}$ & - & $13.4 \mu \mathrm{V}$ & $0.569^{* *}$ & $\leq 13.0 \mu \mathrm{V}$ \\
\hline & & $L^{*}$ & - & $13.2 \mu \mathrm{V}$ & & \\
\hline & CV & $\mathrm{R}$ & - & $51.6 \mathrm{~m} / \mathrm{s}$ & $0.022^{* *}$ & $<49.0 \mathrm{~m} / \mathrm{s}$ \\
\hline & & $L$ & - & $49.4 \mathrm{~m} / \mathrm{s}$ & & \\
\hline \multirow[t]{6}{*}{ Radial } & $\mathrm{SDL}$ & $\mathrm{R}^{*}$ & $2.13 \mathrm{~ms}$ & - & $0.513^{* *}$ & $>2.40 \mathrm{~ms}$ \\
\hline & & $L$ & $2.40 \mathrm{~ms}$ & - & & \\
\hline & Amplitude & $\mathrm{R}$ & - & $15.7 \mu \mathrm{V}$ & $0.770^{* *}$ & $\leq 11.5 \mu \mathrm{V}$ \\
\hline & & $L^{*}$ & - & $11.7 \mu \mathrm{V}$ & & \\
\hline & CV & $\mathrm{R}$ & - & $56.4 \mathrm{~m} / \mathrm{s}$ & $0.217^{* *}$ & $\leq 55.0 \mathrm{~m} / \mathrm{s}$ \\
\hline & & $L$ & - & $55.1 \mathrm{~m} / \mathrm{s}$ & & \\
\hline \multirow[t]{3}{*}{ Sural } & SDL & $\mathrm{R}^{*}$ & $3.33 \mathrm{~ms}$ & - & - & $\geq 3.40 \mathrm{~ms}$ \\
\hline & Amplitude & $\mathrm{R}^{*}$ & - & $9.3 \mu \mathrm{V}$ & - & $\leq 9.0 \mu \mathrm{V}$ \\
\hline & $\mathrm{CV}$ & $\mathrm{R}^{*}$ & - & $42.1 \mathrm{~m} / \mathrm{s}$ & - & $\leq 42.0 \mathrm{~m} / \mathrm{s}$ \\
\hline
\end{tabular}

*Variables with non-Gaussian distribution; **ight to left difference with Gaussian distribution: one-sample t-test; ${ }^{*}$ right to left difference with non-Gaussian distribution one-sample Wilcoxon test. SDL: sensory distal latency (onset measured); CV: conduction velocity; R: right; L: left.

Table 3. Median and ulnar motor nerve conduction parameters in 30 healthy elderly subjects: 60 limbs (30 right and 30 left sides).

\begin{tabular}{|c|c|c|c|c|c|c|}
\hline Nerve & Variable & Side & $97.5 \%$ & $2.5 \%$ & $\mathrm{p}$-value & Abnormal \\
\hline \multirow[t]{8}{*}{ Median } & MDL & $\mathrm{R}$ & $4.26 \mathrm{~ms}$ & - & $0.584^{* *}$ & $\geq 4.30 \mathrm{~ms}$ \\
\hline & & $L$ & $4.21 \mathrm{~ms}$ & - & & \\
\hline & Amplitude & $\mathrm{R}$ & - & $9.5 \mathrm{mV}$ & $0.111^{* *}$ & $<8.0 \mathrm{mV}$ \\
\hline & & $\mathrm{L}$ & - & $8.0 \mathrm{mV}$ & & \\
\hline & Blockage & $R^{*}$ & $23.3 \%$ & - & $0.805^{\#}$ & $\geq 24.0 \%$ \\
\hline & & $L$ & $13.9 \%$ & - & & \\
\hline & $\mathrm{CV}$ & $R^{*}$ & - & $50.0 \mathrm{~m} / \mathrm{s}$ & $0.125^{* *}$ & $<50.0 \mathrm{~m} / \mathrm{s}$ \\
\hline & & $\mathrm{L}$ & - & $50.0 \mathrm{~m} / \mathrm{s}$ & & \\
\hline \multirow[t]{8}{*}{ Ulnar } & MDL & $\mathrm{R}$ & $3.58 \mathrm{~ms}$ & - & $0.107^{\#}$ & $\geq 3.60 \mathrm{~ms}$ \\
\hline & & $L$ & $3.53 \mathrm{~ms}$ & - & & \\
\hline & Amplitude & $\mathrm{R}$ & - & $10.6 \mathrm{mV}$ & $0.045^{* *}$ & $<9.9 \mathrm{mV}$ \\
\hline & & $\mathrm{L}$ & - & 9.9 mV & & \\
\hline & Blockage & $\mathrm{R}$ & $15.7 \%$ & - & $0.014^{* *}$ & $\geq 16.0 \%$ \\
\hline & & $L$ & $15.3 \%$ & - & & \\
\hline & $C V$ & $\mathrm{R}$ & - & $51.4 \mathrm{~m} / \mathrm{s}$ & $0.576^{* *}$ & $<50.0 \mathrm{~m} / \mathrm{s}$ \\
\hline & & $\mathrm{L}$ & - & $50.0 \mathrm{~m} / \mathrm{s}$ & & \\
\hline
\end{tabular}

*Variables with non-Gaussian distribution; ${ }^{* *}$ right to left difference with Gaussian distribution: one-sample t-test; ${ }^{*}$ right to left difference with non-Gaussian distribution: one-sample Wilcoxon test. MDL: motor distal latency; CV: conduction velocity; R: right; L: left. 
Table 4. Comparative reports for upper limit of normality (95\%) in carpal tunnel syndrome electrodiagnosis.

\begin{tabular}{lccccc}
\hline & Our data** $^{*}$ & Ref 25 & Ref 23 & Ref 18 & Ref 24 \\
\hline $\mathrm{n}$ & 30 & 38 & 65 & 15 & 80 \\
$\mathrm{Age}$ & $65-86$ & $21-69$ & $40^{*}$ & $20-48$ & $20-73$ \\
$\mathrm{SDL}$ & 3.80 & 3.48 & - & - & - \\
$\mathrm{MDL}$ & 4.26 & 3.71 & - & - & 4.20 \\
$\mathrm{MPL}$ & 2.43 & 2.27 & - & - & - \\
MUD & 0.93 & 0.35 & 0.40 & - & - \\
MRD & 0.93 & 0.37 & 0.50 & - & - \\
MUPD & 0.49 & 0.31 & 0.30 & - & - \\
CSI & 2.18 & - & 1.10 & - & - \\
LUMB & 0.60 & - & - & 0.50 & - \\
\hline
\end{tabular}

*Not published; **higher value from right and left. SDL: median sensory distal latency; MPL: median mixed palmar latency; MUD: median to ulnar nerve sensory difference (ring finger); MRD: median to radial sensory difference (thumb); MUPD: median to ulnar mixed palmar difference; CSI: combined sensory index; LUMB: median to ulnar lumbrical-interossei difference; MDL: median motor distal latency.

\section{DISCUSSION}

Carpal tunnel syndrome is a common cause of upper limb sensory symptoms, mainly the hands, and its diagnostic confirmation depends on $\mathrm{NCS}^{1,2,14}$. The normal limits for most CTS electrodiagnosis techniques were not defined for the elderly ${ }^{15,20-23}$. With an increasing life expectancy, the use of reference parameters derived from the current limits could increase the number of false-positive CTS electrodiagnoses.

Our results confirm distinct values for CTS electrodiagnosis in the elderly. Table 4 compares some reference values derived from our study to the results of younger populations ${ }^{18,23-25}$. The greatest differences were obtained with sensory and mixed comparative techniques. Median nerve SDL, MPL, and the LUMB had smaller differences compared with values for younger persons, and MDL was the only technique that showed a very slight change in the elderly compared with values for younger persons.

As recommended by Robinson and Dorfman ${ }^{19}$, we analyzed each variable and tested whether or not the observed values fit a normal distribution ${ }^{19,26}$. We applied Gaussian statistics to normal distributions and nonGaussian statistics to non-normal distributions, avoiding a common source of error when dealing with reference values ${ }^{19,26}$. Right and left sides were studied separately and normal values were determined for each side ${ }^{27}$.

There are few studies establishing nerve conduction reference parameters specifically for the elderly popula$\operatorname{tion}^{28-30}$. We did not find a normative study specifically for CTS electrodiagnosis using comparative techniques in the elderly. In the literature review by the American Association of Neuromuscular \& Electrodiagnostic Medicine (AANEM) for CTS electrodiagnosis ${ }^{15}$, reference values were not found for the elderly, except for one study where the authors studied median-radial sensory difference and stratified abnormal values by age group ${ }^{31}$. Their results cannot be compared with ours because of the use of an orthodromic technique and the inclusion of individuals less than 65 years of age ${ }^{31}$. Moreover, the hand temperature was maintained at less than $32^{\circ} \mathrm{C}$.

Falco et al..$^{28}$ established normal parameters for upper limb electrodiagnostic studies in healthy elderly subjects. These authors studied upper limb sensory and motor nerve conduction techniques, but comparative CTS electrodiagnosis techniques were not studied. For this reason, and because of methodological differences, only the median nerve MDL and MCV could be compared with our results, and were higher and lower, respectively, than ours. In Australia, Hamilton-Bruce et al..$^{29}$ studied upper and lower limb nerve conduction parameters in the elderly. Because of differences in nerve conduction techniques, only the median nerve MDL could be compared with our results. Their value was higher than ours, probably because of different selection criteria, which allowed diabetic volunteers to be included, and a lower mean limb temperature.

In our study, sural SNAPs were easily obtained in all subjects (100\%) with standard electrophysiological techniques using a recordable percutaneous bar electrode. Although it was commonly accepted in the past that the absence of sural SNAP may not indicate an abnormality in older individuals, it probably no longer can be accepted ${ }^{32}$. This finding is in accordance with a study by Falco et al. ${ }^{30}$ in 122 healthy elderly subjects, where they obtained sural SNAPs in $98 \%$ of the participants.

Aging affects the peripheral nervous system, changing nerve conduction parameters ${ }^{33}$. Previous studies linked the aging process to the motor and sensory conduction 
velocities with amplitudes declining and distal latencies increasing ${ }^{16}$. More recently, the most striking change was observed in the sensory amplitude, which declines about $50 \%$ after the age of 70 ; motor and sensory conduction velocities had a lesser decrease (10-20\%). Also, the aging effect was unequally distributed on different peripheral nerves ${ }^{17,20-22,33}$. Our results partially confirm the latter point, because of the greatest differences were in sensory and mixed comparative techniques versus absolute latencies. Another possible explanation for the discrepancies observed between these techniques could be the presence of asymptomatic carpal tunnel median compressive neuropathy in spite of all volunteers had denied any kind of symptoms related to this condition. Because of gender discrepancies, we believe that in older women comparative techniques should be analyzed with some caution.

In conclusion, the results of this study showed distinct electrophysiological values for CTS diagnosis in the elderly, especially according to mixed and sensory comparative techniques. These normative parameters will be useful to diagnose mild cases when CTS electrodiagnosis is used in patients over 65 years of age. They can also be used to reduce the number of false-positives electrodiagnoses. Additional studies will be necessary to determine the sensitivity and specificity of our data.

\section{REFERENCES}

1. Bland JDP. Carpal tunnel syndrome. BMJ 2007;335:343-346.

2. Kouyoumdjian JA. Síndrome do túnel do carpo. Arq Neuropsiquiatr 1999: 57:504-512.

3. Rodner CM, Katarincic J. Open carpal tunnel release. Tech Orthopaedics 2006; 21:3-11.

4. Stevens JC, Sun S, Beard CM, O'Fallon WM, Kurland LT. Carpal tunnel syndrome in Rochester, Minnesota, 1961 to 1980. Neurology 1988;38:134-138.

5. Nordstrom DL, DeStefano F, Vierkant RA, Layde PM. Incidence of diagnosed carpal tunnel syndrome in a general population. Epidemiology 1998;9:342-345

6. Bland JDP, Rudolfer SM. Clinical surveillance of carpal tunnel syndrome in two areas of the United Kingdom, 1991-2001. J Neurol Neurosurg Psychiatry 2003;74:1676-1679.

7. Blumenthal S, Herskovitz S, Verghese J. Carpal tunnel syndrome in older adults. Muscle Nerve 2006;34:78-83.

8. Gelfman R, Melton LJ 3rd, Yawn BP, Wollan PC, Amadio PC, Stevens JC. Long term trends in carpal tunnel syndrome. Neurology 2009;72:33-41.

9. Atroshi I, Gummesson C, Johnsson R, Ornstein E, Ranstam J, Rosén I. Prevalence of carpal tunnel syndrome in a general population. JAMA 1999;282:153-158.

10. De Krom MCTFM, Knipschild PG, Kester ADM, Thus CT, Boekkooi PF, Spaans F. Carpal tunnel syndrome: prevalence in the general population. J Clin Epidemiol 1992:45:373-376.

11. Nora DB, Becker J, Ehlers JA, Gomes I. Clinical features of 1039 patients with neurophysiological diagnosis of carpal tunnel syndrome. Clin Neurol Neurosurg 2004; 107:64-69.

12. Phalen GS. The carpal tunnel syndrome: seventeen years' experience in diagnosis and treatment of six hundred fifty-four hands. J Bone Joint Surg Am 1966;48:211-228.

13. Seror P. Carpal tunnel syndrome in the elderly "Beware of severe cases". Ann Hand Surg 1991;10:217-225.

14. Jablecki CK, Andary MT, Floeter MK, et al. Practice parameter: electrodiagnostic studies in carpal tunnel syndrome Report of the American Association of Electrodiagnostic Medicine and Rehabilitation. Neurology 2002;58:1589-1592.

15. Jablecki CK, Andary MT, Floeter MK, et al. Second AAEM literature review of the usefulness of nerve conduction studies and needle electromyography for the evaluation of patients with carpal tunnel syndrome. Muscle Nerve 2002;26(Suppl):S924-S978.

16. Norris AH, Shock NW, Wagman $\mathrm{H}$. Age changes in the maximum conduction velocity of motor fibers of human ulnar nerves. J Appl Physiol 1953;5:589-593.

17. Lee $\mathrm{KW}, \mathrm{OH} \mathrm{SJ}$. Early appearance of aging phenomenon in the interdigital nerves of the foot. Muscle Nerve 1994;17:58-63.

18. Al-Shekhlee A, Fernandes JA, Sukul D, Preston DC. Optimal recording electrode placement in the lumbrical-interossei comparison study. Muscle Nerve 2006;33:289-293.

19. Dorfman LJ, Robinson LR. AAEM minimonograph \# 47: normative data in electrodiagnostic medicine. Muscle Nerve 1997;20:4-14.

20. Buschbacher RM. Median 14-cm and 7-cm antidromic sensory studies to digits two and three. Am J Phys Med Rehabil 1999;78(Suppl):S53-S62.

21. Buschbacher RM. Median nerve motor conduction to the abductor pollicis brevis. Am J Phys Med Rehabil 1999;78(Suppl):S1-S8.

22. Buschbacher RM. Mixed nerve conduction studies of the median and ulnar nerves. Am J Phys Med Rehabil 1999;78(Suppl):S69-S74.

23. Robinson LR, Micklesen PJ, Wang L. Strategies for analyzing nerve conduction data: superiority of a summary index over single tests. Muscle Nerve 1998; 21:1166-1171.

24. De Léan J. Transcarpal median sensory conduction: detection of latent abnormalities in mild carpal tunnel syndrome. Can J Neurol Sci 1988;15:388-393.

25. Jackson DA, Clifford JC. Electrodiagnosis of mild carpal tunnel syndrome. Arch Phys Med Rehabil 1989;70:199-204.

26. Robinson LR, Temkin NR, Fujimoto WY, Stolov WC. Effect of statistical methodology on normal limits in nerve conduction studies. Muscle Nerve 1991; 14:1084-1090.

27. Padua L, Pasqualetti P, Rosenbaum R. One patient, two carpal tunnels: statistical and clinical analysis - by hand or by patient? Clin Neurophysiol 2005; 116:241-243.

28. Falco FJE, Hennessey WJ, Braddom RL, Goldberg G. Standardized nerve conduction studies in the upper limb of the healthy elderly. AM J Phys Med Rehabil 1992;71:263-271.

29. Hamilton-Bruce MA, Black AB, Duong L, Purdie GH. Peripheral nerve conduction in the elderly: reference data and comparison with patients with carpal tunnel syndrome. Med Sci Res 1996;24:491-494.

30. Falco FJ, Hennessey WJ, Goldberg G, Braddom RL. Standardized nerve conduction studies in the lower limb of the healthy elderly. Am J Phys Med Rehabil 1994;73:168-174.

31. Carrol GJ. Comparison of median and radial nerve sensory latencies in the electrophysiological diagnosis of carpal tunnel syndrome. Electromyogr Clin Neurophysiol 1987;68:101-106.

32. Oh SJ. Physiological factors affecting nerve conduction. In: Clinical Electromyography: Nerve Conduction Studies. $3^{\text {rd }}$ Ed. Philadelphia: Lippincott Williams \& Wilkins 2003; 334-337.

33. Valério BC, Nóbrega JA, Tilbery CP. Condução nervosa em nervos da mão e o fator fisiológico idade. Arq Neuropsiquiatr 2004;62:114-118. 